$\underline{\text { Juegos caballerescos en el origen del teatro áulico }}$

By: Ignacio Lopez Alemany

Alemany, L. I. "Juegos caballerescos en el origen del teatro áulico.” [Chivalric Games in the Origin of Court Theater]. Bulletin of the Comediantes 58.2 (2006): 307-22.

Made available courtesy of Bulletin of the Comediantes:

http://dx.doi.org/10.1353/boc.2006.0032

****) Bulletin of the Comediantes. Reprinted with permission. No further reproduction is authorized without written permission from Bulletin of the Comediantes. This version of the document is not the version of record. Figures and/or pictures may be missing from this format of the document. $* * *$

Abstract:

Tradicionalmente se pensó que el teatro de nuestro Siglo de Oro era hijo de una 'laicización' de un primitivo teatro religioso, el cual—según se explicaba—a causa de un progresivo alejamiento de lo sacro hubo de sacarse primero a los portales de las iglesias, y después a las plazas (Chambers 182; Crawford 137-59). Sin embargo, cuando hace ya algunos años empezó a ponerse en una mejor perspectiva la importancia de la secularización de las formas dramáticas religiosas en el origen del teatro español y se distinguió entre el teatro religioso dentro de la Iglesia y aquel que — si bien con temas más o menos religiosos — se desarrollaba dentro del palacio cortesano, se descubrió el importante papel que desempeñó el inmenso número de prácticas de tipo escénico y espectacular iniciadas en los palacios cortesanos $^{1}$ de la Edad Media y desarrolladas durante el siglo XVI en el camino hacia la comedia barroca (Wardropper, Varey, Shergold, Arróniz, Froldi, Surtz, Rozas, Oleza, Ferrer Vails, Álvarez Pellitero, et al.).

\title{
Article:
}

****Note: Full text of article below 


\section{JUEGOS CABALLERESCOS EN EL ORIGEN DEL TEATRO ÁULICO}

\section{IGNACIO LÓPEZ ALEMANY \\ Duke University}

Tradicionalmente se pensó que el teatro de nuestro Siglo de Oro era hijo de una 'laicización' de un primitivo teatro religioso, el cual—según se explicaba - a causa de un progresivo alejamiento de lo sacro hubo de sacarse primero a los portales de las iglesias, y después a las plazas (Chambers 182; Crawford 137-59). Sin embargo, cuando hace ya algunos años empezó a ponerse en una mejor perspectiva la importancia de la secularización de las formas dramáticas religiosas en el origen del teatro español y se distinguió entre el teatro religioso dentro de la Iglesia y aquel que-si bien con temas más o menos religiosos-se desarrollaba dentro del palacio cortesano, se descubrió el importante papel que desempeñó el inmenso número de prácticas de tipo escénico y espectacular iniciadas en los palacios cortesanos ${ }^{1}$ de la Edad Media y desarrolladas durante el siglo XVI en el camino hacia la comedia barroca (Wardropper, Varey, Shergold, Arróniz, Froldi, Surtz, Rozas, Oleza, Ferrer Valls, Álvarez Pellitero, et al.).

Dentro de estas actividades iniciadas en el Medioevo, se estudiaron inicialmente los "momos" como precedente inmediato de lo que se llamaba "drama" propiamente dicho (Asensio). A pesar del esfuerzo de los investigadores, aún quedan por ser estudiadas en profundidad muchas de las influencias que sobre el teatro de corte tuvieran entretenimientos tales como la música vocal romancística, la danza, los combates de a pie y de 
a caballo, y otros ejercicios de los llamados "pasos de armas" como los torneos y las justas.

$\mathrm{Si}$, además, tenemos en cuenta que los estudios de los últimos años parecen confirmar que las cortes renacentistas del siglo XVI—n lo que se refiere a la configuración del fasto y a la diversión de sus miembrosson una continuación de aquellas del medioevo tardío (Asch), parece bastante lógico buscar en aquellos entretenimientos áulicos los orígenes de éstos, pues en el caso de algunas de estas diversiones, la sola presencia o incluso participación del monarca y los cortesanos, dibujarían los primeros trazos de nuestra dramaturgia cortesana del Renacimiento. Hace ya algún tiempo Shergold (140) explicaba en su monumental obra que la historia del espectáculo medieval coincide con la del fasto de las fiestas públicas y privadas, religiosas y civiles. Ahora bien, esta historia común continúa a lo largo del siglo XVI y se desarrollan en tres cauces que, de forma más o menos dramática, se encontrarán repetidamente en tensión para lograr la supremacía social sobre los demás. De un lado tenemos el modelo populista heredado de los juglares y asentado en el teatro religioso del siglo XV y XVI; de otra parte, el cortesano de tipo privado o de fasto $\mathrm{y}$, por último, la línea erudita desarrollada en círculos de humanistas a través de lecturas y representaciones de obras griegas y latinas. De entre estas tres prácticas dramáticas será la de tradición cortesana la que "desplegándose a lo largo del siglo XVI, se verá obligada a salir a la calle en el último cuarto de siglo para ganar la batalla de la hegemonía del teatro público, y esa salida de los palacios determinará en una dosis decisiva el carácter de las primeras formulaciones de la comedia barroca: las de Tárrega y su escuela y las del propio Lope" (Oleza, "Hipótesis" 13-14). Esta tradición cortesana tiene dos vertientes principales: la del fasto y la de la fiesta.

De entre los fastos medievales, las entradas reales mantuvieron siempre su vocación pública, al ser utilizadas por los reyes como un instrumento de comunicación con las clases urbanas, ya que el rey, a la vez que mostraba su esplendor y compartía su alegría por una victoria, un matrimonio, u otra ocasión festiva, lograba el agradecimiento y sumisión del pueblo a través de estas "operaciones de prestigio" (Strong 7-11, 42-50; Ferrer, "La fiesta" 155).

Las fiestas cortesanas, por el contrario, ya sean privadas o públicas, suponen siempre una "contracción estamental" frente a las celebraciones de la plaza pública o, incluso eclesiásticas (Álvarez Pelletero 91), pues lo 
que sucede en el interior de los muros del palacio no puede ser accesible a todos. Es más, aun en los casos en que las celebraciones cortesanas tienen lugar fuera del recinto cortesano, el pueblo llano no actúa sino como "comparsa acompañante" o mero "espectador", ya que, por definición, la fiesta cortesana está realizada desde y para la corte. Las celebraciones cortesanas, por tanto, tratarán primordialmente de señalar a los cortesanos como un grupo selecto, una sociedad mítica, que difiera esencialmente del resto de la población pues-como escribe Juan del Encina-la corte encuentra su base y origen en la persona real y por tanto, al ser el rey su raiz y centro, no puede ser sino una excepcional cuajada de virtudes:

...donde está todo el valer, el valer y el merecer de todo merecimiento.

Allí es corte real donde el rey y reina fueren; adonde ellos estuvieren, es nuestro bien principal. (Encina 367)

El autor valenciano Luis Milán, en la "epistola proemial" al rey Felipe Il que encabeza su Cortesano (1561), no duda en trazar una genealogía mítica de la sociedad cortesana. En ella emparenta al hombre de palacio con el "cavallero armado y virtuoso" (Aii) que salvara la ciudad de Roma en la historia de Marco Curcio narrada por Plutarco y Tito Livio en la Historia Natural. ${ }^{2}$ Según esta leyenda, el soldado romano se sacrificó arrojándose vestido con el uniforme, y a caballo, a una sima que se había abierto en una plaza de Roma y que, según había predicho el oráculo, sólo se cerraría cuando la ciudad arrojara dentro lo mejor que tuviera. Acto seguido, la sima se cerró, y esto fue interpretado como representación de la máxima nobleza porque, el caballero armado y virtuoso es, sin duda, lo mejor que todo pueblo posee. En la genealogía de Luis Milán, sin embargo, este caballero será aún mejorable en el siglo XVI ya que ahora, "para ser perfecto, [el caballero] habrá de ser cortesano" (A2).

Para los cortesanos, como legítimos herederos de la caballería $y$, por consiguiente, también de aquellos guerreros como Marco Curcio, el torneo será la actividad que mejor refleje su carácter exclusivo pues en él, al contrario de lo que vimos sucedía en las entradas reales, no hay diálogo posible con el pueblo llano sino que constituye una mera actividad auto- 
complaciente de la clase más privilegiada (Asch 10). De hecho, a partir del siglo XIII se procuró, mediante reglamentos-curiosamente recopilados en el siglo XVII con el nombre de teatros-que los burgueses no tomaran parte en estos pasos de armas ya que, en celebraciones como la de la fiesta del Espinette de Lille, los burgueses mostraron claramente sus aspiraciones de ascenso social al probar que ellos también podían actuar de modo idéntico al de los caballeros (Flores Arroyuelo 269). Como consecuencia de esto, se hizo necesaria la prohibición específica a los caballeros de luchar contra aquellos que no formaran parte de la caballería. ${ }^{3}$

Estas aspiraciones de la burguesía, reflejadas en la imitación de las costumbres y modos caballerescos-junto con la exclusiva normativa que como reacción genera en los tratados de caballería - causan que la ceremonia de justas y los torneos se complique y enriquezca sobremanera para representar una "diferencia" no ya tanto de clase, como de naturaleza respecto de la burguesía, y marcar de esta manera el abismo que va entre unos hombres que viven en condiciones casi "preternaturales" y los otros que, a causa del pecado de Eva, se encuentran "condenados a trabajar".4

En estos pasos de armas, por consiguiente, se ignora conscientemente a la burguesía y a la ciudad. Se puede utilizar su espacio para llevarlo a cabo, como en el juego de "moros y cristianos" que organizara el condestable de Castilla don Miguel Lucas de Iranzo en 1463 (Hechos 18286) ocupando la totalidad de la ciudad de Jaén como una extensión de su propio palacio y, así, "representar" una típica lucha fronteriza entre moros y cristianos. ${ }^{5}$ En casos como éste, la ciudad no será una entidad propia de la burguesía y distinta del palacio. Muy al contrario, no será sino un patio de juegos para los cortesanos.

En aquella ocasión narrada por Pedro de Escavias, alcaide de Andújar-según la atribución de Mata y Carriazo-cerca de doscientos caballeros participaron bien "en abito morisco, de barbas postizas" o como caballeros cristianos para representar un complejo juego de cañas en el que encontramos ya numerosos detalles caballerescos y dramáticos. De entre los que representan a los moros, uno finge ser el rey de Marruecos, mientras que otro representa al propio Mahoma. Llegado el momento, unos sirvientes del supuesto rey de Marruecos avanzan hacia el palacio del Condestable donde, en presencia de su familia y de sus caballeros, le desafian a un juego de cañas. El objetivo de este juego-competición, será el de adivinar qué dios sea más poderoso, si el de los cris- 
tianos o el de los musulmanes. El Condestable de Castilla acepta el reto y el juego tendrá lugar, durante más de tres horas, en la plaza de Santa María.

Como es lógico, salen vencedores los caballeros cristianos y-una vez derrotadas las tropas musulmanas-se adelantan los que representan al rey de Marruecos y Mahoma y se paran ante el Condestable, reniegan de su fe en el Islam y arrojan al suelo un ejemplar del Corán, para convertirse en cristianos y pedir el bautismo al Condestable de Castilla porque, dicen, "vuestro Dios voss ayuda, por do se deve creer que vuestra ley es mejor que la nuestra" (186). Todos estos fingidos moros se acercan entonces a besar la mano del Condestable, con lo que mediante la fingida derrota y sumisión vasallático-religiosa del rey de Marruecos y Mahoma al condestable se pretende reforzar la autoridad de don Miguel Lucas de Iranzo y presentarlo como un gran héroe cristiano imprescindible para concluir la campaña de la Reconquista. Toda esta celebración, como es menester en los fastos medievales, se concluye con gritos y canciones que -según dice la crónica-acompañan a las danzas hasta el amanecer.

Con esta puesta en escena, el condestable de Castilla se defendía de la oposición y acoso del obispo de Jaén y, sobre todo, del marqués de Villena, a la sazón maestre de Santiago, que trataban de desbancarle con la intención de lograr el control de la región y asegurarse así el botín de una futura toma de Granada (Ruiz 302). El juego de cañas nos muestra al Condestable casi como un rey bíblico, protegido por Dios y clemente con sus enemigos, si bien antes se asegura su fidelidad mediante un inteligente besamanos de sus fingidos enemigos, a la vez que prefigura una futura conquista del suculento reino granadino.

En lo dramático, se crean unos personajes-si bien es cierto que aún planos y arquetípicos-y se utiliza un cierto atrezzo, como son las barbas o el ejemplar del Corán y "otros libros de su ley"; se crea un pequeño argumento de estructura simple que se repetirá en numerosas ocasiones en la siguiente centuria (Ferrer Valls, La práctica 19-35). En primer lugar, se inicia la representación con la "carta de desafio", que suele ser leída frente al señor y describe el motivo de la celebración, a la vez que explica las normas con las que se ha de proceder durante la misma. Posteriormente tienen lugar los enfrentamientos con los diálogos intercalados para, una vez concluidos los combates, celebrarse un fin de fiesta en el que no faltan nunca canciones y bailes. Por tanto, estos juegos representacionales ocupan normalmente dos espacios: el primero suele ser una 
sala del interior del palacio, donde tiene lugar el desafío; en el segundo, se desarrollan los combates o enfrentamientos, las canciones y las danzas. ${ }^{6}$

Como se ve, estos pasos de armas han dejado de ser exclusivamente un entrenamiento militar de los caballeros, y su conjunción con los diálogos y progresiva "novelización" lo harán apartarse de lo castrense para incorporarlo a los nuevos "entretenimientos cortesanos" que intentan mostrar al rey o al señor como fuente de las dos características básicas del "caballero cristiano"; esto es, el honor y la virtud. De los pasos de armas - como de tantas otras prácticas tardomedievales-el Renacimiento adopta sólo las estructuras básicas para después modificarlas y estilizarlas hasta convertirlas en "nuevos" rituales puramente cortesanos. No obstante, y a pesar de este edulcoramiento del factor castrense en los pasos de armas-ya advertido fuera de nuestras fronteras por Alfonso X en Las Partidas (Part. II, Tit. XXIII, XXVII)- estas artes marciales siguieron siendo vistas fundamentalmente como un hecho militar hasta el siglo XVII. ${ }^{7}$ Sin embargo, ya a finales del siglo XIV, de entre los pasos de armas, sería específicamente el torneo el que desarrollaría un sentido más dramático que debió de ser fundamental para el nacimiento del drama cortesano y de la comedia caballeresca (Egido 13; Ferrer Valls, La práctica 19-35; Attolini 189-203). Ahora bien, cuál y cómo es la relación entre los torneos festivos y el teatro es algo aún pendiente de ser analizado en términos dramatológicos. Es necesario conocer qué elementos de uno son aprovechados por el otro y de qué manera sea eso posible.

La celebración de los torneos se constituye en este momento como una parte integral de un espectáculo más amplio que no habría de limitarse tan sólo a lo castrense, sino que también sería una magnífica ocasión para el lucimiento del rey y de los caballeros, los cuales, mediante su dominio del caballo y las armas, manifestaban también el monopolio de la fuerza y la violencia, a la vez que hacían ostentación de su riqueza con espléndidos vestuarios, o mostraban su excelencia cortesana respetando el enrevesado ritual caballeresco, o exhibian de complejas divisas, motes y empresas, etc. (Pérez Samper 176; Cátedra 97-98), y así "ilustrar" su virtud y su condición "preternatural", como dije anteriormente. Para estas celebraciones, como se ha dicho, se preparaba un mínimo argumento dramático apoyado por un aparato escenográfico que permitiera un mayor desarrollo del componente ficticio del juego. En Valladolid se celebró un gran número de estas fiestas caballerescas entre 1517 y 1518 , aunque sin lugar 
a dudas, los preparativos más lucidos se hicieron para el frustrado torneo con motivo del bautizo del príncipe Felipe en 1527:

El Serenísimo Emperador tenía concertados torneos y aventuras de la manera que Amadis (muy más fieros y graciosos que en el dicho libro lo cuenta), así que ni antes ni después nunca tales fiestas se hicieron ni se harán. (Zúñiga 181)

Esta celebración-explica el cronista-fue interrumpida por Carlos V tras conocerse la noticia del saco de Roma:

... hobo dello tanto pesar e hizo tanto sentimiento, que otro día que las aventuras se comenzaron, y así mismo los torneos, los mandó cesar; $\mathrm{y}$ derribar los tablados y castillos, $\mathrm{y}$ asimismo los palenques $y$ otros edificios que para las fiestas se habían hecho, en que se habían gastado gran suma de dinero. (181)

Más adelante, en el año 1544, en la misma ciudad vallisoletana, el Almirante de Castilla, don Luis Enríquez, ofreció un torneo al príncipe Felipe y a su mujer María de Portugal que se comenzó con la entrada de un enano montado sobre una hidra de siete cabezas y de raso verde "pintada muy al natural y echando fuego por todas la bocas" (Alenda y Mira 42) que se dirigió a la puerta del palacio llevando a la princesa una carta de desafio planteada en términos mitológicos que reunían la mitología pagana y la caballería, como más tarde lo harán las comedias cortesanas. En esta ocasión, para ver espectáculo, el público se repartió entre las ventanas del patio, donde se situaron también doña María y sus damas, a la vez que la nobleza en cadalsos con doseles y brocados cercando el lugar de la representación. El patio, cuando se habilitaba a manera de sala, esto es, entoldado e iluminado convenientemente, era-al igual que el claustro eclesiástico-un lugar ideal para las representaciones teatrales. De él salían escaleras que se dirigían a las distintas dependencias, sus puertas y diferentes niveles permitían una rica diversidad en el juego teatral y, como en esta ocasión, lograba una separación del público en distintos niveles y dependencias que posibilitaba su utilización con fines propagandísticos (Cruziani; Sirera) que, cuando se construyeron los primeros teatros permanentes de la villa de Madrid durante la década de 1580 , se respetó aunque con lógicas adiciones en los criterios de organización del 
público tales como el "corredor de mujeres", el orden de entradas y salidas del recinto, etc. ${ }^{8}$

En este momento, los ejercicios de armas que estudiamos parecen haberse alejado ya bastante de aquella función originaria de entrenamiento para la guerra para acercarse hacia lo que Kowzan considera plenamente un simple espectáculo. ${ }^{9}$ Es decir, "una manifestación cuyo desarrollo y final están previstos y ordenados de antemano" (45) ya que en este momento el ganador de cada combate estaría fijado previamente, como en el caso de la representación organizada por don Miguel Lucas de Iranzo. En aquella ocasión, recordémoslo, los dos fingidos moros entregaron al condestable una "carta de desafío" en la que su rey pedía al condestable:

'... que vuestros cavalleros cristianos con los mis moros jueguen cañas, e si en aquesto como en la guerra vuestro Dios vos ayuda a levar lo mejor, luego el nuestro profeta Mahomad e los libros de nuestra ley que conmigo mandé traer serán de mí e de mis moros renegados. E por mí e por ellos desde aquí me someto a ser vuestra ordenança et mandado, et de vos conosçer vasallaje, et de reçibir vuestra cristiandad en el río o do devamos ser bautizados. (Hechos 99-100)

Es decir, en ningún momento se contemplaba la posibilidad de una victoria de las tropas del rey de Marruecos. No hubo entonces verdadero "desafío", sino fingido; y no pudo haber tampoco verdadera competición, ni tan siquiera juego, sólo representación.

Estas exhibiciones espectaculares de torneos que ahora nos ocupan son, por lo general, presentadas dentro de un hilo argumental de tipo caballeresco muy débil que, en ocasiones, no es más que una sucesión de carros en los que tienen lugar los combates. Sin embargo, es la semilla arrojada que, cuando cae en tierra buena, con el tiempo, florece en una historia de mayor riqueza dramática. Tal fue el caso de la primitiva Comedia de don Duardos de Gil Vicente, cuya dramatización de un fragmento del Primaleón le permitió al autor portugués construir una trama "novelesca" que impregnara toda la representación: el caballero que oculta su identidad para hacerse pasar por un hombre más humilde, la intervención mágica de la "copa", el cortejo de la dama, etc. y, sobre todo, de una manera muy especial, los combates a espada que desencadenarán la 
acción de la comedia, al enamorarse Duardos de Flérida durante el primero de estos (vv. 430-35).

Cuan largo fueran normalmente los lances de espada en este tipo de representaciones no podemos saberlo con certeza, pero sí tenemos constancia de que parte del público los disfrutaba como algo central del entretenimiento, aunque las damas preferían que fueran acompañados de cierta "historia amorosa". No así la princesa Maria de Portugal quien, por el contrario, según el testimonio que tenemos de los torneos celebrados en 1543 en Salamanca, disfrutó más que ninguna otra cosa "los doce caballeros que salieron a tornear del interior de un castillo asaltado por una cuadrilla y una sierpe que lanzaba fuego" (Ferrer Valls, La práctica 23).

Sin embargo, como contraposición al caso de María de Portugal tenemos lo que sucedió en el Palacio Real de los virreyes valencianos Fernando de Aragón y Germana de Foix, donde tenían lugar numerosos "combates de a pie" como parte integrante de sus abundantes entretenimientos. Una noche, durante la representación de una máscara, conocida como la Máscara de los griegos y los troyanos, los cortesanos valencianos-disfrazados de tal guisa-representaban las luchas entre estos dos pueblos en el jardín del Palacio Real. Aquella noche, los combatientes se lanzaron con tal ferocidad unos contra otros que las damas, nos relata el texto de Luis Milán, hubieron de apartar la vista de los combatientes en repetidas ocasiones $y$, el virrey-cuando las damas amenazaban ya con desmayar-hubo de ordenar el cese de las luchas:

Ya que todos fueron entrados, estando donde havían de combatir, hecha que fue la señal, vinieron con muy gran gana uno para el otro, el Rey Príamo Troyano y el Rey Agamenón Griego, y en haver ronpido sus picas pusieron mano a las espadas, que gran espanto ponian los golpes que se davan, y el duque mandó señalar al trompeta, por que las damass havian perdido la color de sus caras dela ferozidad dellos, y cessaron de combatir. (C4; énfasis mío)

Y no nos debe de extrañar que así fuera, ya que-como también Milán menciona-la fiereza de los combates era tal que "temblando estaban las hojas de los árboles" e incluso estropeó la iluminación que para la máscara se había preparado, pues "el grande ayre que levantaron del combatir, la mayor parte de las lumbres mataron" [C5']. 
En otra ocasión, en este mismo palacio, se llevó a cabo la escenificación de la llamada Farsa de las galeras de Sanct Joan (K2- L8), en la que unos caballeros acometen el rescate de unas damas retenidas por los turcos. Entre los combatientes de ambos bandos hay siempre un brevísimo diálogo en el que cada cristiano apremia al correspondiente turco que libere a la dama y se convierta al cristianismo según la convención caballeresca de permisión de un último arrepentimiento y conversión. ${ }^{10} \mathrm{~A}$ continuación, y sin que medie palabra por parte del "infiel", tiene lugar el enfrentamiento individual entre ambos en el que siempre vence el cristiano. Una vez finalizado cada combate, el caballero se dirige a su dama cantando un villancico que es, a su vez, contestado por ésta.

Una vez vencidos los turcos y recuperadas las mujeres, el capitán pide al virrey que los turcos sean liberados "por haber visto cara de rey". Ellos, entonces, llenos de agradecimiento, bailan para el virrey una "morisca", mientras los cristianos celebran entre ellos un torneo de a pie. Este nuevo "torneo de a pie" no tiene, naturalmente, ya conexión alguna con el entrenamiento castrense, sino que es exclusivamente coreográfica, al igual que "la morisca" ejecutada por los fingidos turcos. Por último, el público asistente-que es exclusivamente cortesano-es invitado a participar del conocido baile de tradición italiana, con lo que se cierra el entretenimiento de un modo similar a como ya ocurriera en la celebración del palacio jienense del Condestable de Castilla.

Sin embargo, al contrario que el castellano, el virrey Fernando de Aragón, que se encontraba sentado sobre un estrado elevado junto a su esposa Germana de Foix, posiblemente no formó parte de la danza, ya que estas representaciones estaban diseñadas para la contemplación del rey, en este caso su alter ego. Esto es, para que pudiese observar desde una posición elevada desde donde poder apreciar mejor las figuras llevadas a cabo, junto con el colorido espectáculo de los disfraces de los turcos y los caballeros (Nevile 818).

Luis Milán, el artífice de estos festejos que acabo de referir, es, sin duda, más conocido como músico que como dramaturgo, y durante aquel tiempo estuvo especialmente activo en cuanto a lo que creación musical se refiere, publicando su Libro del Maestro de vihuela (1536), del que numerosas piezas son interpretadas en otras celebraciones de aquel mismo año, por lo que no sería de extrañar que alguna de sus composiciones fuera el acompañamiento de los villancicos cantados por los caballeros, pues la farsa en sí no es sino una sucesión de villancicos y comba- 
tes finalizados con la referida coreografia del baile a la morisca y el torneo de los caballeros. La estilización del torneo medieval alcanza aquí un hito importante, pues se resume en un espectáculo que contiene una gran cantidad de elementos provenientes de la primitiva danza en la que, por ejemplo, cada uno de los tres grupos de personas que intervienen (soldados, damas y turcos) entran y salen de escena siempre como una sola persona. En más de una ocasión se ha sugerido que incluso todo el espectáculo estuviera concebido como las danzas "moriscas" italianas del siglo $\mathrm{XV}$ que, tal vez, traerían a la memoria del virrey sus días como príncipe de Nápoles antes de que le fuera arrebatado el trono a manos del Gran Capitán. Esta danza cortesana, que tradicionalmente se interrumpe para dar paso a breves interludios dramáticos, no obstante, se extendió rápidamente más allá de las fronteras italianas, y no solamente hacia España, sino que incluso María de Hungría llegó a organizar "danzas moriscas" para agasajar a su hermano el emperador Carlos V y a su hijo Felipe II durante su visita a la ciudad de Bins, Bélgica, en 1549.

Durante aquella misma estancia del Emperador, su hermana le obsequió también con unos torneos, que fueron "en imitación de los libros de Amadís", por los que la familia tenía especial gusto. Tras el sarao, alguien entrega la carta del desafío al Emperador, la cual es leída en alta voz, y dice así:

A la "Gallica Bélgica", junto a la villa de Bins, se ha venido a recoger un encantador, enemigo de la caballería, llamado Noramoch, que ha cometido grandes males secuestrando caballeros y nobles de esa provincia de Su Majestad. Noramoch habita en el castillo tenebroso, llamado así por estar cubierto de una espesa nube. Para llegar allí, los esforzados caballeros deberán atravesar diferentes pasos: la isla venturosa, la torre peligrosa, y el paso afortunado. (Calvete Estrella 182)

La carta entonces termina estableciendo las reglas de cada uno de los juegos. Escenográficamente es una celebración mucho más complicada que la que organizó en Valladolid el propio Carlos V en 1527. Estos torneos ya han empezado a dar una mayor cabida a lo iconográfico y al complejo desarrollo de textos en forma de monólogos e, incluso, diálogos, junto con explicaciones ante un público cada vez más variado en el que parece pensarse más (Cátedra 111). En este punto de la investigación de la his- 
toria del drama español, pues, el debate sobre si estos torneos deban o no ser catalogados como auténtico teatro, se torna estéril, pues en nada contribuye a su conocimiento.

Mucho más fructífero me parece que es, como se ha pretendido aquí, tratar de determinar hasta qué punto estos torneos (fueran propiamente dramáticos o no) contenían en sí mismos la posibilidad de desarrollarse hasta convertirse en 'comedias', como la de Don Duardos, una vez que asimilan el mundo literario de tema caballeresco. En la comedia del portugués, por ejemplo, ya no se trata únicamente de duplicar o de re-presentar, un espacio físico y un orden social, ni de que unos actores encarnen virtudes o mitos folklore o la historia colectiva. Muy al contrario, encontramos, $y$ tal vez por primera vez como apunta Shergold (135), una incipiente y moderna preocupación por el desarrollo de unos personajes ya conocidos de antemano por la literatura caballeresca. El interés dramático de los espectadores, por consiguiente, ya no puede centrarse únicamente en el placer del simple espectáculo, sino en el desarrollo y acción del personaje y, con él, necesariamente de la trama, lo que devendrá en el uso de nuevos recursos dramáticos tales como la intriga, la sorpresa, y una comicidad impensable en el teatro anterior. Ello, propiciado por esa simiente caballeresca que late en el corazón de comedias como la de Don Duardos y, más adelante, de las así llamadas comedias caballerescas como Las suertes trocadas, El torneo venturoso o El Prado de Valencia del canónigo Tárrega, La suerte sin esperanza de Gaspar Aguilar, El desengaño dichoso de Guillén de Castro, El premio de la hermosura de Lope y El caballero del Sol de Luis Vélez de Guevara, o El castillo de Lindabridis de Calderón, entre un largo etcétera (Ferrer Valls, La práctica 34-35). De esta forma, los pasos de armas y otras artes marciales caballerescas encontrarían en su "literaturización" una vía para seguir siendo una parte importante de la vida cortesana cuando su necesidad militar decreció a causa del desarrollo tecnológico y los consecuentes cambios en la estrategia bélica, para la que ya no eran necesarios los grupos organizados de caballeros armados que en fila acometiesen al enemigo lanza en ristre (Cátedra 96).

Al igual que Norbert Elias señalaba a la ritualización de las ceremonias de la mesa como una sublimación de la violencia por parte del rey sobre la nobleza para ejercer su poder, también es posible considerar que la "manipulación artística" de la lucha bélica por parte de los reyes y nobles cumplió una función de sublimación y propaganda - casi por sugestión- 
dirigida a los rivales dentro de la corte $y$, como no, a la pujante burguesía, pues, las aventuras caballerescas representadas en las tablas no eran sino un sueño; el sueño heroico-caballeresco de un Emperador y de una clase nobiliar cuya función militar estaba íntimamente vinculada a su posición en la corte, la cual defenderían, aunque tuvieran que salir a luchar a los mismísimos corrales.

\section{NOTAS}

1. Algunos críticos, como Humberto López Morales, no obstante, niegan la existencia de un drama medieval que no sea el litúrgico (71); Alan Deyermond, por su parte, tampoco acepta la teatralidad de los tomeos o los espectáculos de corte del tipo de los realizados en el palacio del condestable de Castilla Miguel Lucas de Iranzo, a los que considera únicamente como "parateatrales" (39-56).

2. Este origen mítico de la excelente condición del "caballero armado" es, no obstante, un tópico de la época que puede encontrarse en La Araucana de Ercilla o, en el declinar del reinado de Felipe II, en Luis Zapata, Miscelánea o Varia historia. MS 2790 de la BNE, fols. 182-83.

3. Recúerdese aquí, que en el combate entre Camilote y Robusto en la Tragicomedia de Don Duardos, antes de enfrentarse en justa de armas, Don Robusto le dice a su oponente: "¿Sois cavallero? / Si lo sois, juro a Dios / que os haga yo tornar / majadero [villano]" (vv. 333-36). El lector del Quijote, recordará también que nuestro hidalgo hizo valer en más de una ocasión su condición de caballero ordenado para no luchar contra villanos en socorro de su escudero.

4. Zapata en su Miscelánea (183) es muy explícito en este sentido, acusando a los burgueses de "pelados" que se meten "en exerçiçio ageno".

5. Para un estudio de la corte del Condestable desde la teatralidad, véase J. Oleza, "Fastos cortesanos".

6. En otras ocasiones, a la lectura de la carta de desafio en el espacio privado, los tomeos en el espacio público de la plaza, etc., pueden volverse al interior de palacio para concluir con los bailes.

7. Un ejemplo curioso a este respecto es el del propio emperador Carlos V que el 17 de abril de 1536, en presencia del Papa Pablo III, la asamblea de cardenales y diplomáticos, retó al rey francés, Francisco I, a un duelo singular para dirimir sus diferencias por la alianza de éste último con Barbarroja (véase Salinas a Fernando I, Roma, 22 de abril de 1536, en Rodriguez Villa 713).

8. Parte de la bibliografla esencial a este respecto la constituyen Allen, Reconstruction y "Primeros"; Middleton; y García García.

9. Aunque esta definición de espectáculo sea, a mi entender, imperfecta, ya que dejaria fuera de la categoría - como viera Garcia Barrientos (48)—algunas expresiones improvisadas como la comedia 
dell'arte, happenings, etc. No obstante, para el propósito de esta investigación es suficiente puesto que lo que interesa es sustraer los torneos de la categoría en la que se encontraban anteriormente; esto es, la de "competición".

10. Encontramos episodios de conversiones en casi todas las novelas de caballerias: Tirant, Esplandián, Lepolemo (El Caballero de la Cruz), Belianís, o en el propio Amadís de Gaula.

\section{OBRAS CITADAS}

Alenda y Mira, J. Relaciones de solemnidades y fiestas públicas de España. 2 vols. Madrid: Sucesores de Rivandeneyra, 1903.

Allen, John J. "Los primeros corrales de comedias: dudas, enigmas, desacuerdos". Edad de Oro 16 (1997): 13-28.

The Reconstruction of a Spanish Golden Age Playhouse: El corral del Principe (1583-1744). Gainesville: UP of Florida, 1983.

Álvarez Pellitero, Ana María. "Pervivencias e innovaciones en el tránsito del teatro religioso medieval al primer Renacimiento". Cultura y representación en la Edad Medieval. Proc. II Festival de Teatre i Música Medieval d'Elx. Octubre-Noviembre, 1992. Ed. Evangelina Rodriguez Cuadros. Alicante: Generalitat Valenciana, 1994. 89-99.

Asch, R. G., y A. M. Birke. Princes, Patronage and the Nobility. The Court at the Beginning of the Modern Age. New York: Oxford UP, 1991.

Asensio, Eugenio. "De los momos cortesanos a los autos caballerescos de Gil Vicente". Estudos Portugueses. Paris: Centro Cultural Português, 1974. 25-36.

Attolini, Giovanni. Teatro e spettacolo nel Rinascimiento. Bari: Laterza, 1988.

Calvete Estrella, Juan Critoval. El felicissimo viaje del mui alto y muy poderoso principe don Phelipe, hijo del emperador don Carlos Quinto Maximo, desde España a sus tierras de la Baja Alemania: con la descripción de todos los estados de Brabante y Flandes. Amberes, 1552.

Cátedra, Pedro M. "Fiestas caballerescas en tiempos de Carlos V". La fiesta en la Europa de Carlos V. Sevilla: Sociedad Estatal para la Conmemoración de los Centenarios de Felipe II y Carlos V, 2000. 93-117.

Cruziani, Fabrizio. "Per lo studio del teatro rinascimentale: la festa". Biblioteca Teatrale 5 (1972): 116.

Deyermond, Alan. "Teatro, dramatismo, literatura: criterios y casos discutibles". Cultura y representación en la Edad Medieval. Proc. Il Festival de Teatre i Música Medieval d'Elx. OctubreNoviembre, 1992. Ed. Evangelina Rodríguez Cuadros. Alicante: Generalitat Valenciana, 1994. 39-56.

Egido, Aurora. Bosquejo para una historia del teatro en Aragón hasta fines del siglo XVIII. 
Zaragoza: Diputación Provincial-Institución Fernando el Católico, 1987.

Encina, Juan del. Obra completa. Ed. M. A. Priego. Madrid: Fundación Antonio de Castro, 1996.

Ferrer Valls, Teresa "La fiesta civica en la ciudad de Valencia en el siglo XV". Cultura y representación en la Edad Medieval. Proc. II Festival de Teatre i Música Medieval d'Elx. OctubreNoviembre, 1992. Ed. Evangelina Rodriguez Cuadros. Alicante: Generalitat Valenciana, 1994. 145-69.

. La práctica escénica cortesana: De la época del Emperador a la de Felipe III. London: Tamesis, 1991.

Flores Arroyuelo, Francisco J. "El torneo caballeresco: De la preparación militar a la fiesta y representación teatral". Medioevo y literatura. Actas del $V$ Congreso de la Asociación Hispánica de Literatura Medieval. Granada, 27 septiembre -1 octubre, 1993. Granada: Universidad de Granada, 1993. 257-78.

García Barrientos, José Luis. Drama y tiempo. Madrid: Consejo Superior de Investigaciones Cientificas, 1991.

García García, B. J. "El teatro de las comedias del Principe (1582-1607)". Manuscrit.Cao. 6 (199495): 5-24.

Hechos del Condestable don Miguel Lucas de de Iranzo. Ed. Juan de Mata Carriazo. Madrid: EspasaCalpe, 1940.

Kowzan, Tadeusz. Littérature et spectacle. La Haya-Paris: Mouton, 1975.

López Morales, Humberto. Tradición y creación en los orígenes del teatro castellano. Madrid: Ediciones Alcalá, 1968.

Middleton, T. The Urban and Architectural Enviroment of the Corrales of Madrid: The Corral de la Cruz in 1600. Los Angeles: $U$ of California P, 1976.

Milán, Luis. Libro Intitulado El Cortesano. Valencia, 1561.

Nevile, Jennifer. "Dance and the Garden: Moving and Static Choreography in Renaissance Europe". Renaissance Quarterly 52.3 (1999): 805-36.

Oleza, Joan. "Fastos cortesanos y teatralidad religiosa. Vinculaciones medievales." Ceti sociali ed ambienti urbani nel teatro religioso europeo del ' 300 e del '400. Actas del Congreso. Ed. M. Chiabò y F. Doglio. Viterbo: Union Printing Editrice, 1986. 265-94.

. "Hipótesis sobre la génesis de la comedia barroca y la historia teatral del XVI". Teatros y prácticas escénicas I: el Quinientos valenciano. Ed. Joan Oleza et al. València: Institució Alfons el Magnànim, 1984. 9-41.

Pérez Samper, María de los Ángeles. "Barcelona, corte: Las fiestas reales en la época de los Austrias". La fiesta cortesana en la época de los Austrias. Ed. Maria Luisa Lobato y Bernardo J. García García. Valladolid: Junta de Castilla y León-Consejería de Cultura y Turismo, 2003. $139-92$.

Rodriguez Villa, Antonio. El Emperador Carlos Vy su Corte según las cartas de don Martín de Salinas. Madrid: Fortanet, 1903. 
Ruiz, Teofilo R. "Elite and Popular Culture in Late Fifteenth-Century Castilian Festivals: The Case of Jaén". City and Spectacle in Medieval Europe. Ed. Barbara A. Hannawalt y Kathryn L. Reyerson. Minneapolis: U of Minnesota P, 1994. 296- 318.

Shergold, N. D. A History of the Spanish Stage. Oxford: Oxford UP, 1967.

Sirera, Josep Lluis. "El teatro en la corte de los duques de Calabria". Teatro y prácticas escénicas $I$. El quinientos valenciano. Ed. Joan Oleza et al. València: Institutió Alfons el Magnànim, 1984. 259-80.

Strong, Roy. Art and Power. Renaissance Festivals (1450-1650). Berkeley y Los Angeles: U of California P, 1984.

Surtz, Ronald. The Birth of a Theater. Princeton: Princeton UP, 1979.

Vicente, Gil. Teatro castellano. Ed. Manuel Calderón. Barcelona: Crítica, 1996.

Zapata, Luis de. Miscelánea o Varia historia. Biblioteca Nacional de España, MS 2790.

Zúfiga, Francesillo de. Crónica Burlesca del Emperador Carlos V. Ed. Diana Avalle-Arce. Barcelona: Crítica, 1981. 
Copyright of Bulletin of the Comediantes is the property of Bulletin of the Comediantes and its content may not be copied or emailed to multiple sites or posted to a listserv without the copyright holder's express written permission. However, users may print, download, or email articles for individual use. 